\title{
Assessing the Ecological Quality of Coastal Lagoons of Western Greece: The Response of Benthic Communities to Environmental Variability
}

\author{
G. Fyttis, S. Reizopoulou, and E. Papastergiadou
}

\begin{abstract}
Coastal lagoons are considered naturally stressed systems that experience frequent environmental variations. Benthic macrophyte and macroinvertebrate species were studied seasonally in two coastal lagoons (Kotychi and Prokopos) in Western Greece to investigate spatial and temporal biodiversity patterns. Ruppia cirrhosa, Potamogeton pectinatus and Chironomidae were dominant in both lagoons, while Kotychi was also dominated by Lekanesphaera monodi and Monocorophium insidiosum, and Prokopos by Ostracoda and Lekanesphaera monodi. Species richness, diversity, and abundance of benthic macroinvertebrates were strongly related to aquatic macrophytes and to the degree of communication with the marine environment. Moreover, species richness and abundance of both macrophytes and macroinvertebrates were mainly dependent on depth, temperature, $\mathrm{pH}$ and total suspended materials (TSM). Based on the preliminary results of this study, it appears that the ISD index, based on the biomass size structure of the macroinvertebrate communities, is an appropriate tool for ecological quality assessment.
\end{abstract}

Index Terms-Diversity indices, macroinvertebrates, macrophytes, Mediterranean lagoons.

\section{INTRODUCTION}

Coastal lagoons are dynamic ecosystems characterised by shallow waters and isolated from the open sea through coastal barriers [1]. Therefore, they represent an ecotone between marine, freshwater, and terrestrial ecosystems, presenting some of the typical characteristics of all three [1]. They are naturally enriched areas with unstable environmental conditions because of their shallowness and their confinement from the open sea. Coastal lagoons are subjected to natural disturbance which depends mainly on morpho dynamics and on climatic factors, such as freshwater flooding and summer drought. Due to their location and value, coastal lagoons also suffer from strong human pressures, as they receive organic and mineral nutrients, and are exploited for aquaculture and tourism [2].

Manuscript received on May 15, 2018; revised February 1, 2019. This work received funding from the Research committee of Patras University and from the Grants of Plant Ecology division.

Georgios Fyttis was with the University of Patras, Department of Biology, GR 26504 Patras, Greece. He is now with the Oceanography Center, University of Cyprus, P.O. Box 20537, 1678 Nicosia, Cyprus (e-mail: fyttis.georgios@ucy.ac.cy).

Sofia Reizopoulou is with the Institute of Oceanography, Hellenic Centre for Marine Research, PO Box 712, 19013 Attiki, Greece (e-mail: sreiz@hcmr.gr).

Eva Papastergiadou is with the University of Patras, Department of Biology, University Campus Rio, Patras, GR 26504, Greece (e-mail: evapap@upatras.gr).
In coastal ecosystems, macrophytes are ecosystem engineers that provide habitat and food resources to other organisms. Macroinvertebrates play a key role in the functioning of brackish waters, and are often the main component of animal biodiversity in small water bodies. Diversity and abundance of fauna species is also influenced by the presence of macrophytes, which increase habitat complexity, provide a shelter against predation, and constitute an abundant source of food, as well as breeding areas for the adults. In highly productive lagoon systems, the primary producers are predominantly rooted macrophytes, macroalgae or phytoplankton, depending on nutrient levels and salinity [2], [3]. What is more, benthic macroinvertebrates and macrophytes have become tools for the classification and monitoring of the ecological status of European water bodies, according to the Water Framework Directive 2000/60/EC [4].

In the Mediterranean Sea, coastal lagoons are restricted and often choked (for definition see [1]), with the only exception being deltaic lagoons, which are open and highly dynamic [5]. The diversity, abundance and distribution patterns of benthic flora and fauna are strongly influenced by hydrological and physicochemical processes (degree of confinement, nutrients, Chl-a, total suspended materials, light irradiance, $\mathrm{pH}$, salinity, temperature, and dissolved oxygen). As a result, low values of diversity, low numbers of species and strong dominance of a few species often characterise lagoonal ecosystems [6], [7].

In the current study, aquatic macrophytes and benthic macroinvertebrates were studied seasonally in two coastal lagoons in Western Greece, named Kotychi and Prokopos. This study aims to investigate the environmental variables, which play the most determinant role in the abundance and distribution of the examined biotic elements. A functional index (Index of Size Distribution - ISD) based on biomass size structure of zoobenthic communities has been applied to investigate the ecological quality.

\section{MATERIALS AND METHODS}

\section{A. Study Area}

Prokopos and Kotychi are brackish lagoons, located in the south western part of Achaia (Fig. 1). Both lagoons are protected by the Ramsar convention and the Natura 2000 network. Kotychi is the largest lagoon of Peloponnese (7100 ha), with a mean depth of $0.56 \mathrm{~m}$, and is better connected to the sea. Prokopos covers an area of 1500 ha, has a mean depth of $0.87 \mathrm{~m}$, and a high degree of confinement. 


\section{B. Methods}

Seasonal samplings were carried out during the period 2009-11 in eight sampling sites at Kotychi, and in seven at Prokopos. Macrophytes were sampled using a grab $(20 \mathrm{~cm} \mathrm{x}$ $20 \mathrm{~cm})$ and macroinvertebrates using a box corer $\left(0.03 \mathrm{~m}^{2}\right)$. Three replicates were collected for both biotic elements at each sampling site. At each sampling station, aquatic macrophyte abundance was visually recorded according to a five - level scale $(1=\leq 20 \%, 2=21-40 \%, 33=41-60 \%, 4=$ $61-80 \%, 5=81-100 \%)$.

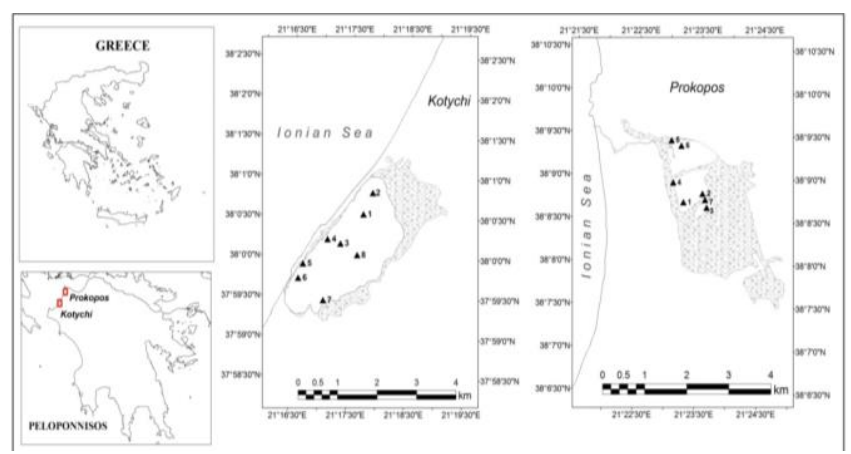

Fig. 1. Map of the studied Kotychi and Prokopos lagoons in Western Greece.

The macroinvertebrate samples were sieved through a $0.5 \mathrm{~mm}$ mesh sieve and stained with Rose Bengal. Samples were preserved in $4 \%$ formalin. In the laboratory, the macrofauna was sorted, identified to species level where possible, and counted. A small amount of sediment was kept for granulometry and analysis of organic carbon. Grain size analysis of the sediment was carried out according to the methods described by Buchanan [8]. Dissolved oxygen at the water surface, dissolved oxygen near the bottom, salinity, conductivity, and temperature, were measured using a portable multimeter instrument YSI. Transparency was measured with a Secchi disk. Additionally, photosynthetically active radiation was measured with a Li-Cor, LI-192SA instrument at four - level depth (0, 10, 20, $30,40 \mathrm{~cm}$ ). Subsequently, the attenuation coefficient K [9] was calculated. Water samples from the sampling stations were also collected for the assessment of nitrates, nitrites, phosphates, total phosphate, ammonium, carbonate, bicarbonate, chlorophyll-a and total suspended materials (TSM) determined according to the analytical procedure of APHA [10]. A small amount of sediment was kept for granulometry and analysis of organic carbon. Grain-size measurements were undertaken using a Sedigraph 5100 system, after the separation of the sand fraction $(>63 \mathrm{~cm})$ by wet sieving. Organic carbon was determined by a Fisons Instruments CHN elemental analyser type EA-1108, following the procedures described by Nieuwenhuize [11].

\section{Data Analysis}

Univariate and multivariate methods were applied for the statistical analyses of the data. Univariate measures included number of taxa, abundance, Shannon-Wiener diversity H' ( $\log _{2}$ basis) and Pielou's evenness J. Community structure was described by multidimensional scaling (MDS), based on a similarity matrix constructed using the Bray-Curtis similarity index. The macrofaunal data were first transformed by $\mathrm{Y}=\log (\mathrm{x}+1)$. Species abundance was investigated using
SIMPER analysis. Redundancy analysis (RDA) and the Mann - Whitney test was used to test relations among biotic and abiotic variables. Data analysis was conducted using SPSS v.19 (Mann - Whitney test), PRIMER v.6 (MDS analysis) and CANOCO 4.5 (RDA analysis).

\section{RESULTS}

The seasonal variation of abiotic parameters and chl-a in the studied lagoons is shown in Table I. Both lagoons presented a wide seasonal and spatial fluctuation of the environmental variables. Both lagoons presented a wide seasonal and spatial fluctuation of the environmental variables. The Mann - Whitney U - test showed that the means of environmental variables depth, the transparency/ depth ratio, the total $\mathrm{P}, \mathrm{Chl}-\mathrm{a}$, and TSM differed significantly between the two lagoons. Prokopos $(0.87 \mathrm{~m})$ is a deeper lagoon than Kotychi $(0.56 \mathrm{~m})$, and thus, it presented higher values of the transparency/depth ratio, as well as of the total P, Chl-a and TSM (Table I).

In total, 22 taxa of aquatic macrophytes (angiosperms and macroalgae), 16 taxa for Kotychi (2 Rhodophyta, 8 Chlorophyta, 5 Magnoliophyta, 1 Streptophyta) and 14 taxa for Prokopos (1 Rhodophyta, 5 Chlorophyta, 5 Magnoliophyta, 3 Streptophyta), were identified. Ruppia cirrhosa, and Potamogeton pectinatus were dominant in both lagoons. The Kotychi lagoon was also dominated by Cladophora glomerata, and Prokopos by Zannichellia pallustris ssp. pedicellata, while in both lagoons, biomass peaked during the summer period.

The total number of macroinvertebrates found in the lagoons was 28 taxa for Kotychi, and 19 for Prokopos. Chironomidae and the isopod Lekanesphaera monodi were dominant in both lagoons, while Kotychi was also dominated by the amphipod Monocorophium insidiosum, and Prokopos by Ostracoda. Benthic diversity (H') ranged from 1.33 to 2.57 in Kotychi, and from 0.67 to 2.48 in Prokopos.

MDS analysis distinguished five macrophyte assemblages (plant Groups) based on 72 sampling plots (Fig. 2). Group I was mainly characterised by the dominance of Zostera noltii, while Groups IIa and IIb were both dominated by Ruppia cirrhosa, but presented different abundances in companion opportunistic species. Group IIIa was dominated by Potamogeton pectinatus and Zannichellia pallustris ssp. pedicellata, and Group IIIb by Zannichellia pallustris ssp. pedicellata and Ulva intestinalis.

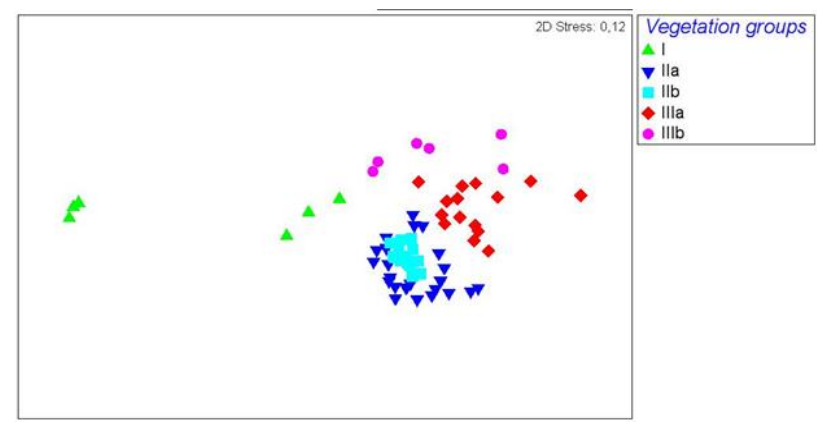

Fig. 2. Multidimensional scaling (MDS) plot of macrophyte assemblages (plant Groups) in the studied lagoons.

The differences in the environmental variables of the 
lagoons were reflected in their benthic fauna. In the MDS of Fig. 3, there is a clear grouping of the stations of each lagoon according to the macroinvertebrates similarities. Group I represents the Kotychi lagoon, which is dominated by
Chironomidae, Lekanesphaera monodi and Monocorophium insidiosum and Group II represents the Prokopos lagoon, dominated by Chironomidae, Ostracoda and Lekanesphaera monodi.

TABLE I: MEAN \pm SD (MIN. - MAX.) VALUES OF ENVIRONMENTAL VARIABLES AND THE STATISTICAL SiGNIFICANCE OF DifFERENCE BETWEEN THE TwO LAGOONS, ACCORDING TO MANN - WHITNEY U - TEST

\begin{tabular}{|c|c|c|c|c|c|c|c|c|c|}
\hline & \multicolumn{4}{|c|}{ Kotychi } & \multicolumn{4}{|c|}{ Prokopos } & \multirow{2}{*}{$\begin{array}{c}\text { Mann-Whitney } \\
\text { P value }\end{array}$} \\
\hline & Min. & Max. & Mean & S.D. & Min. & Max. & Mean & S.D. & \\
\hline Depth (m) & 0.20 & 1.00 & 0.56 & 0.18 & 0.47 & 1.89 & 0.87 & 0.35 & 0.000 \\
\hline Transparency (m) & 0.00 & 0.56 & 0.28 & 0.14 & 0.09 & 0.66 & 0.28 & 0.15 & 0.609 \\
\hline Trans./Depth & 0.00 & 1.00 & 0.54 & 0.30 & 0.05 & 0.83 & 0.36 & 0.21 & 0.003 \\
\hline Temperature $\left({ }^{\circ} \mathrm{C}\right)$ & 11.06 & 32.20 & 20.62 & 6.75 & 12.34 & 30.67 & 20.71 & 6.43 & 0.996 \\
\hline pH & 6.74 & 10.11 & 8.06 & 0.95 & 6.65 & 9.95 & 7.69 & 0.77 & 0.064 \\
\hline D.O. surface (mg/l) & 3.93 & 17.86 & 8.57 & 2.87 & 0.34 & 18.69 & 8.86 & 4.64 & 0.638 \\
\hline D.O. bottom (mg/l) & 2.60 & 24.21 & 8.99 & 5.48 & 0.20 & 21.06 & 8.45 & 5.63 & 0,879 \\
\hline Salinity (psu) & 0.24 & 25.48 & 9.38 & 8.09 & 1.30 & 38.43 & 16.29 & 10.95 & 0.017 \\
\hline $\mathrm{PO}_{4}-\mathrm{P}(\mu \mathrm{g} / \mathrm{l})$ & 4.34 & 264.76 & 86.76 & 70.94 & 2.17 & 538.19 & 100.02 & $\begin{array}{c}140.3 \\
2\end{array}$ & 0.192 \\
\hline Total P $(\mu \mathrm{g} / \mathrm{l})$ & 69.44 & 321.18 & 179.24 & 82.84 & 112.85 & 768.23 & 305.79 & $\begin{array}{c}179.2 \\
6\end{array}$ & 0.001 \\
\hline $\mathrm{NO}_{2}-\mathrm{N}(\mu \mathrm{g} / \mathrm{l})$ & 0.00 & 76.85 & 18.28 & 20.47 & 0.31 & 65.87 & 13.48 & 18.14 & 0.192 \\
\hline $\mathrm{NO}_{3}-\mathrm{N}(\mu \mathrm{g} / \mathrm{l})$ & 8.16 & 730.19 & 112.06 & $\begin{array}{c}158.0 \\
6\end{array}$ & 5.65 & 724.86 & 161.82 & $\begin{array}{c}265.2 \\
2\end{array}$ & 0.174 \\
\hline $\mathrm{NH}_{4}-\mathrm{N}(\boldsymbol{\mu g} / \mathbf{l})$ & 7.57 & 336.94 & 72.77 & 80.26 & 7.57 & $\begin{array}{c}1188.0 \\
1\end{array}$ & 84.99 & $\begin{array}{c}214.3 \\
8\end{array}$ & 0.08 \\
\hline Total N ( $\mu \mathrm{g} / \mathrm{l})$ & 18.24 & 991.25 & 203.11 & $\begin{array}{c}233.6 \\
5\end{array}$ & 16.17 & $\begin{array}{c}1198.0 \\
4\end{array}$ & 260.28 & $\begin{array}{c}329.0 \\
6\end{array}$ & 0,891 \\
\hline Chl-a $\left(\mathrm{mg} / \mathrm{m}^{3}\right)$ & 0.00 & 43.08 & 10.45 & 11.34 & 6.11 & 188.89 & 39.23 & 37.43 & 0.000 \\
\hline TSM (mg/l) & 0.00 & 60.74 & 21.40 & 13.22 & 1.48 & 144.00 & 51.55 & 29.92 & 0.000 \\
\hline tot. Nitrogen (\%) & 0.21 & 0.43 & 0.31 & 0.06 & 0.03 & 1.39 & 0.61 & 0.51 & 0.345 \\
\hline tot. Carbon (\%) & 2.88 & 5.26 & 4.44 & 0.55 & 0.26 & 14.53 & 6.82 & 5.29 & 0.345 \\
\hline org. Carbon (\%) & 1.58 & 3.25 & 2.24 & 0.44 & 0.23 & 10.34 & 5.03 & 3.99 & 0.315 \\
\hline
\end{tabular}

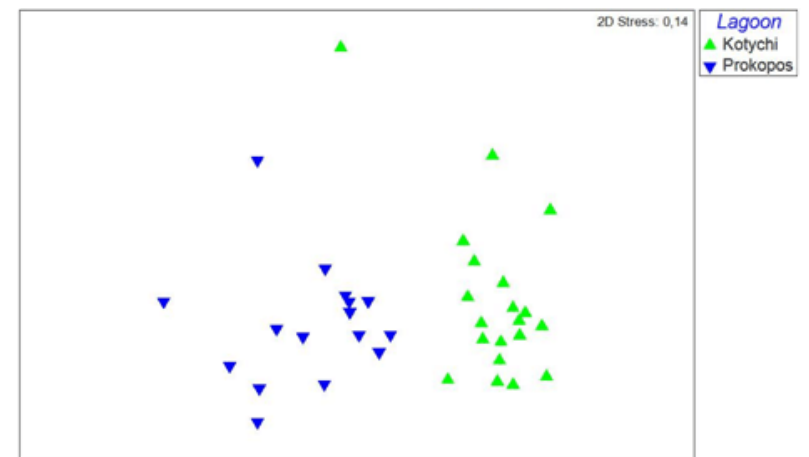

Fig. 3. Multidimensional scaling (MDS) plot of macroinvertebrate fauna in the studied lagoons based on the species abundances.

The results of the RDA between the macrophyte biotic indices (S \& H') and coverage (\%), and the physicochemical parameters, showed that the first two RDA axes explain the $35.1 \%$ of variance of species data and the $99.9 \%$ of species-environment relation (Fig. 4).

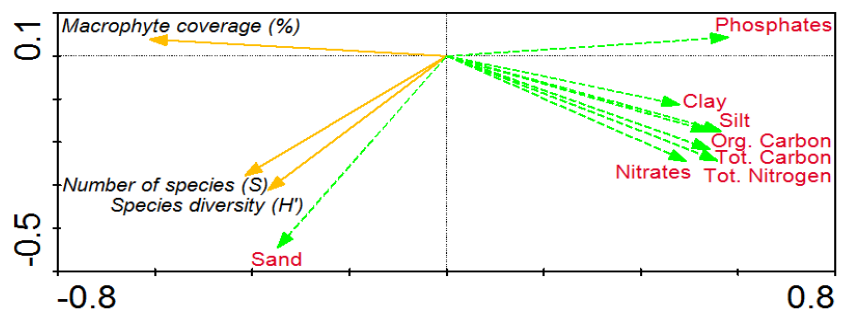

Fig. 4. RDA analysis of macrophyte coverage (\%), species richness (S) and species diversity $\left(H^{\prime}\right)$ with the type of sediment and the nutrients.

The number of macrophyte species (S) and their diversity $\left(H^{\prime}\right)$ were positively related with the percentage of sand, while no significant correlation among nutrients and plant coverage has been found. Macrophyte coverage (\%) showed a negative relation with the percentage of clay and silt, organic carbon in the sediment, total carbon, total nitrogen, phosphates, and nitrates in the water column.

The RDA analysis showed that Chlorophyta prefer muddy sediments and have a positive relation with sediments' parameters (organic carbon, total carbon and total nitrogen). The angiosperms Zannichelia pallustris ssp. pedicellata and Potamogeton pectinatus showed a positive relation with the sand substrate, while Ruppia cirrhosa showed a positive relation with $\mathrm{pH}$, temperature, and salinity (Fig. 5).

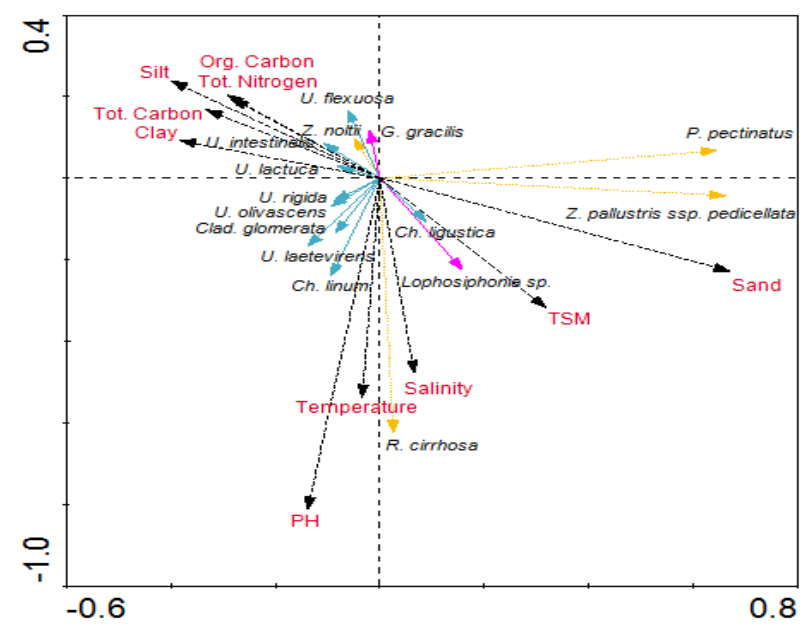

Fig. 5. RDA analysis of aquatic macrophytes with environmental variables.

The results of the RDA between the macroinvertebrate species number $(\mathrm{S})$, diversity $\left(\mathrm{H}^{\prime}\right)$ and density $(\mathrm{N})$ and the physicochemical parameters (Fig. 6) showed that the first two RDA axes explain $50.3 \%$ of the variation in species data 
and $99.7 \%$ of the relation of species-environment. In addition, the RDA analysis showed that macroinvertebrate density $(\mathrm{N})$, diversity (H') and species richness (S) have a positive relation with the bottom's dissolved oxygen and a negative relation with organic carbon, total carbon, total nitrogen, TSM and total P (Fig. 6). Finally, in Fig. 7 the results of the ISD macroinvertebrate index are shown. The Kotychi lagoon has been classified in the category of moderate ecological status, while the Prokopos lagoon, ranged from poor (summer) to good (spring), showing a seasonal variability.

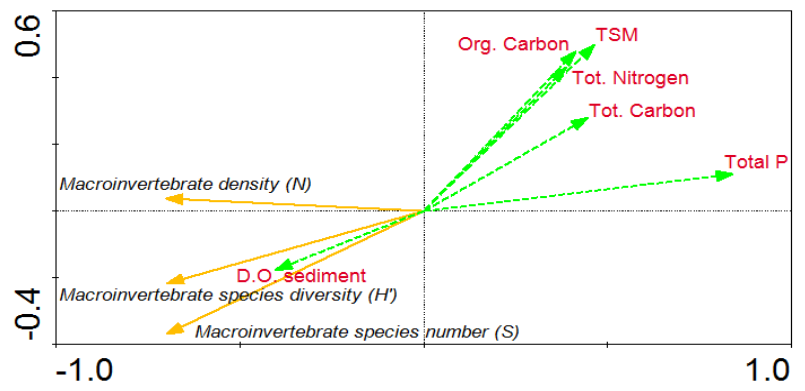

Fig. 6. RDA analysis of macroinvertebrate density (N), Shannon diversity $\left(\mathrm{H}^{\prime}\right)$, and species richness $(\mathrm{S})$ with environmental variables.

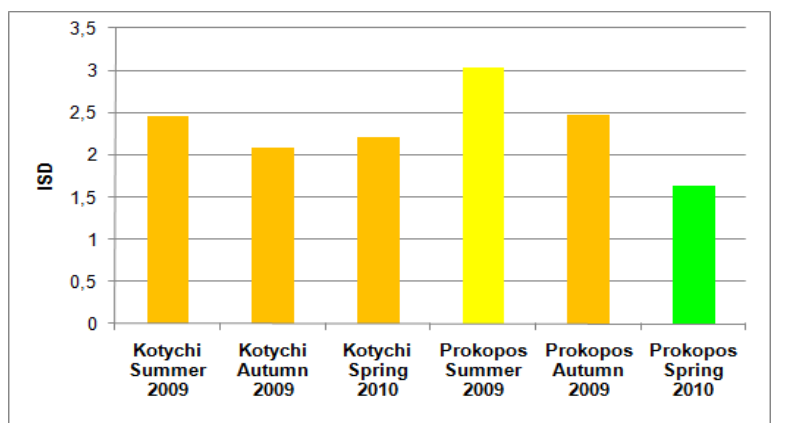

Fig. 7. Seasonal fluctuation of macroinvertebrate ISD index at the studied areas.

\section{DISCUSSION AND CONCLUSIONS}

The results derived from the monitoring of the Kotychi and Prokopos coastal lagoons of Western Greece are representative of several similar Mediterranean ecosystems. These lagoons belong to different lagoon types and reflect the gradient of environmental conditions, typically observed in many transitional water ecosystems due to the mixing of freshwater, seawater and human impacts [3].

In the present study, a different temporal and spatial variation of the environmental variables between the two lagoons has been observed mainly because of their different degree of marine influence. Both lagoons can be characterised as eutrophic, due to high phosphorus and Chl-a concentration. A seasonal and spatial fluctuation of environmental variables in the lagoons influences species richness and abundance. Changes in salinity, water level and oxygen are known to be the important stressors affecting biodiversity in transitional ecosystems [6]. Most notably, Prokopos shows a wider seasonal range of environmental variability and local hypoxic conditions, during the summer period.

Both lagoons showed an almost even seasonal variability in macrophyte and macroinvertebrate community structure, such as low species richness and diversity values, high dominance of a few species, which has also been observed in other Greek lagoons [7], [12]. The Prokopos lagoon presented the lower number of species and Shannon diversity, compared to Kotychi, a fact which could be attributed to the former's higher degree of confinement. Results indicated that both macrophyte and macroinvertebrate species richness (S) and diversity (H') were negatively related with sediment parameters, such as organic carbon, total Carbon and total nitrogen. Macroinvertebrate density $(\mathrm{N})$, species richness $(\mathrm{S})$ and species diversity were strongly related with the dissolved oxygen in the bottom of both lagoons, which is strongly related to the degree of water renewal. The hydrological processes that take place in transitional waters affect the biotic elements and the biological zonation of these ecosystems. The preliminary results indicate that the ISD, based on the biomass size structure of zoobenthic communities, might be an effective tool for the evaluation of the ecological status of these ecosystems. Further investigation is necessary to examine the relationships between hydrological processes and biodiversity patterns, while the use of functional indices could be a promising tool for impact assessment in coastal ecosystems.

\section{REFERENCES}

[1] B. Kjerfve, Coastal Lagoons Processes, Elsevier Oceanography Series 60, Amsterdam, 1994.

[2] P. Viaroli, M. Bartoli, G. Giordani, M. Naldi, and M. J. Zaldivar, "Community shifts, alternative stable states, biogeochemical controls and feedbacks in eutrophic coastal lagoons: a brief overview," Aquatic Conservation: Marine Freshwater Ecosystems, vol. 18, pp. 105-117, 2008.

[3] C. Christia, G. Giordani, and E. Papastergiadou, "Environmental variability and macrophyte assemblages in coastal lagoon types of Western Greece (Mediterranean Sea)," Water, vol. 10, no. 151, 2018.

[4] European Commission, Directive 2000/60/EC of the European Parliament and of the Council Establishing a Framework for the Community Action in the Field of Water Policy, vol. 43, p. 72, 2000.

[5] G. Bellan, Écologie Littorale Méditerranéenne, Bulletin d‘ Écologie, vol. 18, pp. 105-241, 1987.

[6] O. Guelorget, and J. P. Perthuisot, "Le domain paralique. Expression geologique, biologique du confinement," Travaux du Laboratoire de Geologie, Ecole Normale Superieure de Paris, vol. 16, p. 136, 1983.

[7] S. Reizopoulou and A. Nicolaidou, "Benthic diversity of coastal brackish-water lagoons in western Greece," Aquatic Conservation: Marine Freshwater Ecosystems, vol. 14, pp. 93-102, 2004.

[8] J. B. Buchanan, "Sediment analysis," Methods for the Study of Marine Benthos, IBP Handbook 16, $2^{\text {nd }}$ edition, Blackwell Scientific, 1984.

[9] D. Christian and Y. P. Sheng, "Relative influence of various water quality parameters on light attenuation in Indian River Lagoon,', Estuarine, Coastal, and Shelf Science, vol. 57, pp. 961-971, 2003.

[10] APHA, Standard Methods for the Examination of Water and Wastewater, American Public Health Association, New York, 1992.

[11] J. Nieuwenhuize, E. M. Maas, and J. J. Middelburg, "Rapid analysis of organic carbon and nitrogen in particulate materials," Marine Chemistry, vol. 45, pp. 217-224, 1994.

[12] A. Mogias and T. Kevrekidis, "Macrozoobenthic community structure in a poikilohaline Mediterranean lagoon (Laki Lagoon, northern Aegean)," Helgolande Marine Research, vol. 59, pp. 167-176, 2005.

Georgios Fyttis is a research scientist at the Oceanography Center, University of Cyprus and the PhD candidate in the Department of Biological Sciences, University of Cyprus. His research interests include aspects of marine ecology with particular reference to the investigation of benthic and pelagic ecology and biodiversity patterns in transitional and coastal ecosystems, population and community dynamics, evaluation of ecological quality and effects of climate change on coastal ecosystems.

Sofia Reizopoulou has a $\mathrm{PhD}$ in marine biology and is a research director at the Institute of Oceanography in the Hellenic Centre for Marine Research, Greece. She is involved in several National and International projects on 
ecological studies and monitoring of coastal and transitional waters, undertaking WP responsibility, or as scientific responsible for HCMR.

Eva Papastergiadou is an assistant professor at the Department of Biology, University of Patras, Greece. Her research interests are focused on freshwater ecology and management, including functional aspects of lake and river communities, evaluation of ecological quality, dynamics of aquatic vegetation and effects of climate changes on aquatic ecosystems. Her expertise is on ecosystem-scale dynamics in wetlands, while she has been involved in many monitoring projects on the protection, management, rehabilitation, and restoration of aquatic ecosystems. 